\title{
Analisis 5s dan Hirarc Pada Stasiun Kerja Rotary, Dryer dan Veneer Compouser di PT. Asia Forestama Raya Pekanbaru
}

\author{
Merry Siska $^{1)}$,Meydikha Gassani ${ }^{2)}$, \\ ${ }^{1,2}$ Jurusan Teknik Industri, Fakultas Sains dan Teknologi, UIN Sultan Syarif Kasim Riau \\ Jl. HR. Soebrantas KM. 18 No. 155 Simpang Baru, Pekanbaru, 28293 \\ Email: merry.siska@uin-suska.ac.id
}

\begin{abstract}
ABSTRAK
PT. Asia Forestama Raya Pekanbaru merupakan salah satu perusahaan yang memproduksi diantaranya Raw Plywood, Product Secondary Pocess (Polyester Plywood dan Film Face) dan kayu gergajian atau moulding. Penelitian ini dilakukan dengan menerapkan ke perusahaan langsung agar dapat melihat perbandingan dan dampak positif yang diperoleh perusahaan.Sumber data diperoleh berdasarkan observasi dan wawancara kepada kepala stasiun kerja dan para pekerja.Analisis lingkungan kerja dilakukan berdasarkan aspek $5 \mathrm{~S}$ dan tentang keselamatan kerja berdasarkan metode HIRARC.Hasil penelitian menunjukkan bahwa kondisi lingkungan kerja pada perusahaan belum memenuhi kriteria 5S sehingga perlu dilakukan perbaikan. Penerapan keselamatan para pekerja belum maksimal sehingga perusahaan masih memiliki 46,15\% kegiatan dengan potensi bahaya ekstrim, 38,46\% kegiatan dengan potensi bahaya high (tinggi), 11,54\% kegiatan dengan potensi bahaya medium (sedang) dan 3,85\% kegiatan dengan potensi bahaya low (rendah). Implementasi mengenai aspek $5 \mathrm{~S}$ telah dilakukan namun dalam penggunaan alat keselematan kerja harus lebih ditingkatkan dan diprioritaskan kembali.
\end{abstract}

Kata Kunci: Metode 5S (Seiri, Seiton, Seiso, Seiketsu, dan Shitsuke), Ergonomi, HIRARC, K3

\section{Pendahuluan}

Era global menuntut pelaku industri baik perusahaan maupun perorangan untuk terus mempertahankan konsistensi di dunia industri.Berbagai inovasi dan perbaikan terus menerus dilakukan untuk meningkatkan kepuasan konsumen.Perbaikan dalam berbagai aspek produksi sangat perlu dilakukan agar tercipta keadaan kerja yang efektif dan efisien (Widodo, 2014).Industri yang mampu menata, mengelola, sekaligus mengevaluasi perusahaannya secara berkala, maka akan mampu bertahan dalam persaingan yang tinggi. Sedangkan industri yang tidak dapat mempertahankan jalannya produksi dalam berbagai aspek serta tidak melakukan perbaikan-perbaikan yang bertujuan untuk berkembangnya suatu industri, maka akan sangat mudah untuk dikalahkan oleh industri lainnya (Risma, 2009). Namun dibalik kemajuan tersebut ada harga yang harus dibayar oleh masyarakat Indonesia, yaitu dampak negatif yang ditimbulkannya, salah satu diantaranya adalah bencana seperti kecelakaan, pencemaran dan penyakit akibat kerja yang mengakibatkan ribuan orang cidera setiap tahun. Proses pembangunan belum diimbangi dengan peningkatan kesadaran keselamatan dan kesehatan kerja sehingga bahaya dan resikonya terus meningkat (Rimawan, 2015).

PT. Asia Forestama Raya adalah perusahaan yang bergerak dibidang kayu lapis dan triplek. Proses produksinya dimulai dari pengupasan kulit kayu gelondongan hingga menjadi produk kayu lapis ataupun triplek berlangsung secara semi otomasi yang masih memerlukan tenaga manusia. Pada perusahaan ini proses yang berlangsung belum memenuhi konsep 5S serta pekerja yang berada pada lantai produksi tidak menggunakan safety pada saat bekerja sehingga resiko terjadinya kecelakan kerja besar yang mengakibatkan pelayanan yang dihasilkan tidak sesuai dengan yang diharapkan serta dapat menambah biaya yang dikeluarkan.

Hal tersebut dapat dilihat pada stasiunstasiun kerja dimana terdapat serpihan-serpihan kayu sisa hasil pemotongan tidak dibersihkan secara berkala, hal tersebut menyebabkan situasi pada lantai produksi terlihat tidak bersih dan tidak rapi.Serta pekerja yang bekerja pada mesin tersebut tidak menggunakan safety baik sarung tangan, masker, ataupun kacamata.resiko terjadi kecelakaan kerja akibat tidak menggunakan kacamata seperti masuknya debu atau serpihanserpihan kayu dapat mengganggu jalannya proses produksi, begitu juga dengan tangan apabila tidak 
menggunakan sarung tangan, potongan-potongan kayu yang runcing dapat menusuk tangan sehingga proses produksi juga menjadi terganggu. Masker juga merupakan yang penting yang harus digunakan karena pada saat mesin beroperasi maka serpihan-serpihan kecil dari kayu dapat masuk ke dalam saluran pernapasan, dengan begitu keselamatan dan kesehatan kerja menjadi terganggu.

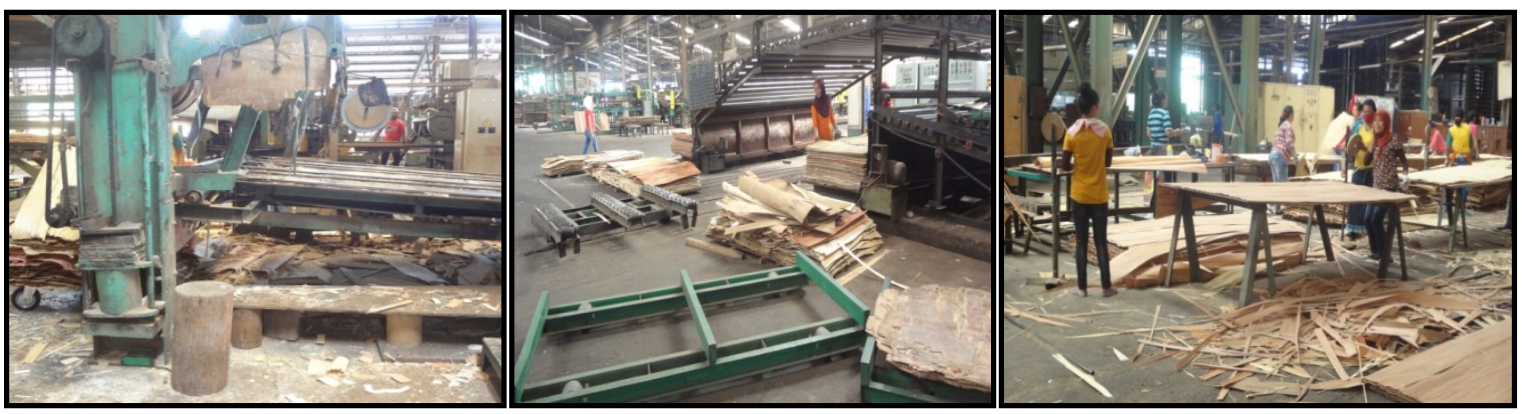

Gambar 1. Kondisi lingkungan kerja yang tidak rapi, tidak bersih

\section{Metode Penelitian}

Metode yang digunakan untuk memperbaiki kondisi lingkungan kerja pada perusahaan ini adalah dengan metode $5 \mathrm{~S}$ yang nantinya akan diterapkan pada stasiun kerja rotary,dryer dan juga veneer compouser. Langkah pertama dalam program $5 \mathrm{~S}$ adalah mempersiapkan mental karyawan dalam menerimanya, sebelum kampanye 5S dilaksanakan. Sebagai upaya pendahuluan 5S, perlu disediakan waktu untuk mendiskusikan falsafah dan manfaat dari 5S, seperti (Rimawan, 2015):

1. Menciptakan lingkungan kerja yang bersih, higienis, aman, dan menyenangkan bagi semua orang.

2. Revitalisasi gemba dan meningkatkan moral karyawan jauh kedepan.

3. Menghapuskan berbagai jenis muda (pemborosan) dengan mengurangi kegiatan mencari-cari peralatan kerja, mempermudah gerak kerja operator, menekan usaha gerak yang menimbulkan rasa tegang dan regangan serta kelelahan industry, dan membebaskan/ mengosongkan tempat.

Menurut Linstiani (2010) dikutip oleh Siska (2012) penjabaran dari metode 5S adalah sebagaimana berikut:

1. Seiri (Sisih atau Ringkas)

Menyisihkan barang-barang yang tidak diperlukan di tempat kerja.Prinsip dalam menerapkan konsep yang pertama ini adalah mengidentifikasi dan menjauhkan barang yg tidak diperlukan di tempat kerja.

2. Seiton (Penataan)

Menata barang-barang yang diperlukan supaya mudah ditemukan oleh siapa saja bila diperlukan.Setiap barang mempunyai tempat yang pasti, jelas dan diletakkan pada tempatnya.Adapun metode yang dapat digunakan adalah pengelompokan barang, penyiapan tempat, memberi tanda batas, memberi tanda pengenal barang, membuat denah atau peta pelaksanaan barang.

3. Seiso (Pembersihan)

Membersihkan tempat kerja dengan teratur sehingga tidak terdapat debu di lantai, mesin dan peralatan. Prinsip: bersihkan segala sesuatu yang ada di tempat kerja. Membersihkan berarti memeriksa dan menjaga.

4. Seiketsu (Pemantapan)

Memelihara taraf kepengurusan rumah tangga yang baik dan organisasi tempat kerja setiap saat. Prinsip: semua orang memperoleh informasi yang dibutuhkan dengan tepat waktu. Pertahankan lingkungan 3S (Sisih, Susun, Sasap) yang telah dicapai, cegah kemungkinan terulang kotor atau rusak.

5. Shitsuke (Pembiasaan)

Memberikan penyuluhan kepada semua orang agar mematuhi disiplin pengurusan rumah tangga yang baik atas kesadaran sendiri. Prinsip: berikan pengarahan kepada orangorang untuk berdisiplin mengikuti cara dan aturan penanganan house keeping atas dasar kesadaran. Lakukan apa yg harus dilakukan dan jangan melakukan apa yang tidak boleh dilakukan.

Pada perusahaan ini juga ditinjau mengenai keselamatan dan kesehatan kerja dari para karyawan.Keselamatan dan kesehatan kerja (K3) merupakan sistem yang melindungi pekerja, perusahaan, lingkungan hidup, dan masyarakat sekitar dari bahaya akibat kecelakaan kerja (Suardi, 2010 dikutip oleh Wijaya, 2015).Perlindungan tersebut merupakan hak asasi 
yang wajib dipenuhi oleh perusahaan.Kecelakaan kerja adalah sesuatu yang tidak terencana, tidak terkontrol, dan sesuatu hal yang tidak diperkirakan sebelumnya sehingga mengganggu efektivitas kerja seseorang (Anton, 1989 dikutip oleh Wijaya, 2015). Penyebab kecelakaan kerja dibagi menjadi lima, yaitu faktor man, toolatau machine, material, method, dan environment dan bahan, faktor lingkungan (Wijaya, 2015).Untuk menganalisa hal-hal-tersebut maka dilakukan analisis menggunakan metode HIRARC.

Metode HIRARC adalah metode yang terdiri dari identifikasi bahaya (hazard identification), penilaian risiko (risk assessment), dan pengendalian risiko (risk control).Potensi penurunan yang dapat terjadi juga perlu dibuat setelah membuat pengendalian resiko. Potensi penurunan dibuat sebagai acuan atau target dari pengendalian yang diterapkan (Wijaya, 2015).

Proses identifikasi bahaya adalah proses lanjutan dari identifikasi kegiatan, pada proses identifikasi bahaya akan dilakukan penjabaran resiko darisetiap kegiatan yang sudah diidentifikasi. Resiko dapat disebabkan oleh beberapa faktor yaitu bahaya fisik, bahaya kimia, bahaya mekanik, bahaya elektrik, bahaya ergonomi, bahaya kebiasaan, bahaya lingkungan, bahaya biologi, dan bahaya psikologi (Wijaya, 2015).Selanjutnya dilakukan penilaian risiko atau yang disebut risk assessment.

Risk assessment adalah proses penilaian yang digunakan untuk mengidentifikasi potensi bahaya yang dapat terjadi.

Acuan yang digunakan untuk melakukan penilaian resiko dapat dilihat pada tabel-tabel dibawah ini (Wijaya, 2015):

Tabel 1.Skala likelihood pada standar AS/NZS 4360

\begin{tabular}{|c|c|c|}
\hline Tingkat & Deskripsi & Keterangan \\
\hline 5 & $\begin{array}{c}\text { Almost } \\
\text { Certain }\end{array}$ & $\begin{array}{c}\text { Terdapat } \geq 1 \text { kejadian } \\
\text { dalam setiap shift }\end{array}$ \\
\hline 4 & Likely & $\begin{array}{c}\text { Terdapat } \geq 1 \text { kejadian } \\
\text { dalam setiap hari }\end{array}$ \\
\hline 3 & Posibble & $\begin{array}{c}\text { Terdapat } \geq 1 \text { kejadian } \\
\text { dalam setiap minggu }\end{array}$ \\
\hline 2 & Unlikely & $\begin{array}{c}\text { Terdapat } \geq 1 \text { kejadian } \\
\text { dalam setiap bulan }\end{array}$ \\
\hline 1 & Rare & $\begin{array}{c}\text { Terdapat } \geq 1 \text { kejadian } \\
\text { dalam setiap tahun }\end{array}$ \\
\hline
\end{tabular}

Tabel 2.Skala Severity pada Standar AS/NZS 4360

\begin{tabular}{|c|c|c|}
\hline Tingkat & Deskripsi & Keterangan \\
\hline 1 & Insignificant & $\begin{array}{c}\text { Tidak terjadi cidera, } \\
\text { kerugian finansial } \\
\text { sedikit }\end{array}$ \\
\hline 2 & Minor & Cedera ringan, kerugian \\
\hline
\end{tabular}

\begin{tabular}{|c|c|c|}
\hline & & finansial sedikit \\
\hline 3 & Moderate & $\begin{array}{c}\text { Cedera sedang, perlu } \\
\text { penanganan medis, } \\
\text { kerugian finansial besar }\end{array}$ \\
\hline 4 & Major & $\begin{array}{c}\text { Cedera berat } \geq 1 \text { orang, } \\
\text { kerugian besar, } \\
\text { gangguan produksi }\end{array}$ \\
\hline 5 & Catastrophic & $\begin{array}{c}\text { Fatal } \geq 1 \text { orang, } \\
\text { kerugian sangat besar } \\
\text { dan dampak sangat luas, } \\
\text { terhentinya seluruh } \\
\text { kegiatan }\end{array}$ \\
\hline
\end{tabular}

(Sumber: Wijaya, 2015)

Tabel 3.Skala Risk Rating pada Standar AS/NZS 4360

\begin{tabular}{|c|c|c|c|c|c|}
\hline Frekuensi & \multicolumn{5}{|c|}{ Dampak Risiko } \\
\cline { 2 - 6 } Risiko & 1 & 2 & 3 & 4 & 5 \\
\hline 5 & $\mathrm{H}$ & $\mathrm{H}$ & $\mathrm{E}$ & $\mathrm{E}$ & $\mathrm{E}$ \\
\hline 4 & $\mathrm{M}$ & $\mathrm{H}$ & $\mathrm{E}$ & $\mathrm{E}$ & $\mathrm{E}$ \\
\hline 3 & $\mathrm{~L}$ & $\mathrm{M}$ & $\mathrm{H}$ & $\mathrm{E}$ & $\mathrm{E}$ \\
\hline 2 & $\mathrm{~L}$ & $\mathrm{~L}$ & $\mathrm{M}$ & $\mathrm{H}$ & $\mathrm{E}$ \\
\hline 1 & $\mathrm{~L}$ & $\mathrm{~L}$ & $\mathrm{M}$ & $\mathrm{H}$ & $\mathrm{H}$ \\
\hline
\end{tabular}

(Sumber: Wijaya, 2015)

Setelah dilakukan penilaian risiko selanjutnya dilakukan pengendalian dari risikorisiko tersebut.Pengendalian resiko adalah cara untuk mengatasi potensi bahaya yang terdapat dalam dalam lingkungan kerja. Potensi bahaya tersebut dapat dikendalikan dengan menentukan suatu skala prioritas terlebih dahulu yang kemudian dapat membantu dalam prioritas terlebih dahulu yang kemudian dapat membantu dalam pemilihan pengendalian resiko yang disebut hirarki pengendalian resiko (Wijaya, 2015).

\section{Hasil dan Pembahasan}

\section{Analisa Metode 5S}

Pengolahan data mengenai kondisi lingkungan kerja dilakukan dengan metode $5 \mathrm{~S}$ yaitu pada stasiun kerja rotary, dryer dan veneercompouser karna stasiun kerja ini yang memiliki kondisi lingkungan kerja yang sangat buruk dan memerlukan perbaikan.Setelah dilakukan analisa mengenai hal-hal yang perlu diperbaiki baik dari segi penataan peralatan, pembersihan lingkungan serta hal-hal lain yang perlu dilakukan perbaikan mengenai kondisi lingkungan maka diperoleh hasil yaitu yang harus dilakukan dari tiap-tiap stasiun kerja dapat dilihat pada tabel 4 . 
Tabel 4. Hasil

\begin{tabular}{|c|c|c|}
\hline $\begin{array}{l}\text { Stasiun } \\
\text { Kerja }\end{array}$ & & Keterangan \\
\hline \multirow{5}{*}{ Rotary } & Seiri & $\begin{array}{l}\text { Menyisihkan gerobak baik yang sudah terisi penuh ataupun yang masih kosong serta } \\
\text { alat-alat lainnya sehingga yang berada pada lantai produksi adalah peralatan yang } \\
\text { digunakan saja }\end{array}$ \\
\hline & Seiton & $\begin{array}{l}\text { Menata atau merapikan gerobak-gerobak yang digunakan serta merapikan bahan atau } \\
\text { material yang berada pada lantai stasiun kerja }\end{array}$ \\
\hline & Seiso & $\begin{array}{l}\text { Membersihkan scrap-scrap sisa pemotongan baik scrap dalam bentuk abu atau pun } \\
\text { scrap dalam bentuk potongan-potongan kecil kayu pada lantai produksi dan pada } \\
\text { mesin yang digunakan }\end{array}$ \\
\hline & Seiketsu & $\begin{array}{l}\text { Melakukan perawatan pada mesin dengan menjaga kebersihan mesin dan area sekitar } \\
\text { stasiun kerja, serta melakukan perawatan terhadap stasiun kerja rotary dengan } \\
\text { menjaga kebersihan dan kerapiannya }\end{array}$ \\
\hline & Shitsuke & $\begin{array}{l}\text { Melakukan penerapan terhadap } 4 \mathrm{~S} \text { sebelumnya dengan penanaman sikap disiplin } \\
\text { kepada para pekerja }\end{array}$ \\
\hline \multirow{5}{*}{ Dryer } & Seiri & $\begin{array}{l}\text { Menyisihkan alas triplek dan gerobak-gerobak alas material serta menyisihkan bahan } \\
\text { atau material yang masih digunakan }\end{array}$ \\
\hline & Seiton & $\begin{array}{l}\text { Merapikan atau menata alas triplek dan gerobak alas pada suatu tempat yang dekat } \\
\text { dengan stasiun kerja serta merapikan tumpukan-tumpukan material atau bahan yang } \\
\text { ada pada stasiun kerja }\end{array}$ \\
\hline & Seiso & $\begin{array}{l}\text { Membersihkan scrap-scrap kayu yang ada lantai stasiun kerja dan yang menempel } \\
\text { pada mesin dryer }\end{array}$ \\
\hline & Seiketsu & $\begin{array}{l}\text { Melakukan perawatan terhadap mesin dengan memebersihkan mesin dari scrap berupa } \\
\text { debu atau serbuk kayu yang menempel serta melakukan perawatan terjadap kebersihan } \\
\text { dan kerapian stasiun kerja }\end{array}$ \\
\hline & Shitsuke & Melakukan pendisiplinan terhadap pekerja dalam menerapkan 4S sebelumnya \\
\hline \multirow{5}{*}{$\begin{array}{c}\text { Veneer } \\
\text { Compouser }\end{array}$} & Seiri & $\begin{array}{l}\text { Menyisihkan spatula, gerobak serta alas triplek yang berserakan pada stasiun kerja } \\
\text { serta menyisihkan bahan atau material yang akan dibawa ke stasiun selanjutnya }\end{array}$ \\
\hline & Seiton & $\begin{array}{l}\text { Merapikan atau menata spatula, alas triplek serta gerobak yang digunakan pada stasiun } \\
\text { kerja serta merapikan bahan atau material yang ada pada stasiun kerja }\end{array}$ \\
\hline & Seiso & $\begin{array}{l}\text { Memberihkan stasiun kerja dari scrap hasil penyisihan bahan atau material serta } \\
\text { menyediakan tempat untuk menampung scrap-scrap yang ada pada lantai stasiun kerja }\end{array}$ \\
\hline & Seiketsu & $\begin{array}{l}\text { Merawat stasiun kerja agar terlihat rapi dan bersih setiap saat serta merawat spatula } \\
\text { dari sisa lem perekat yang menempel pada spatula }\end{array}$ \\
\hline & Shitsuke & $\begin{array}{l}\text { Menerapkan sikap disiplin pada diri pekerja untuk menerapkan 4S sebelumnya pada } \\
\text { staisun kerja }\end{array}$ \\
\hline
\end{tabular}

Tabel 5. Perbandingan sebelum dan setelah dilakukan perbaikan

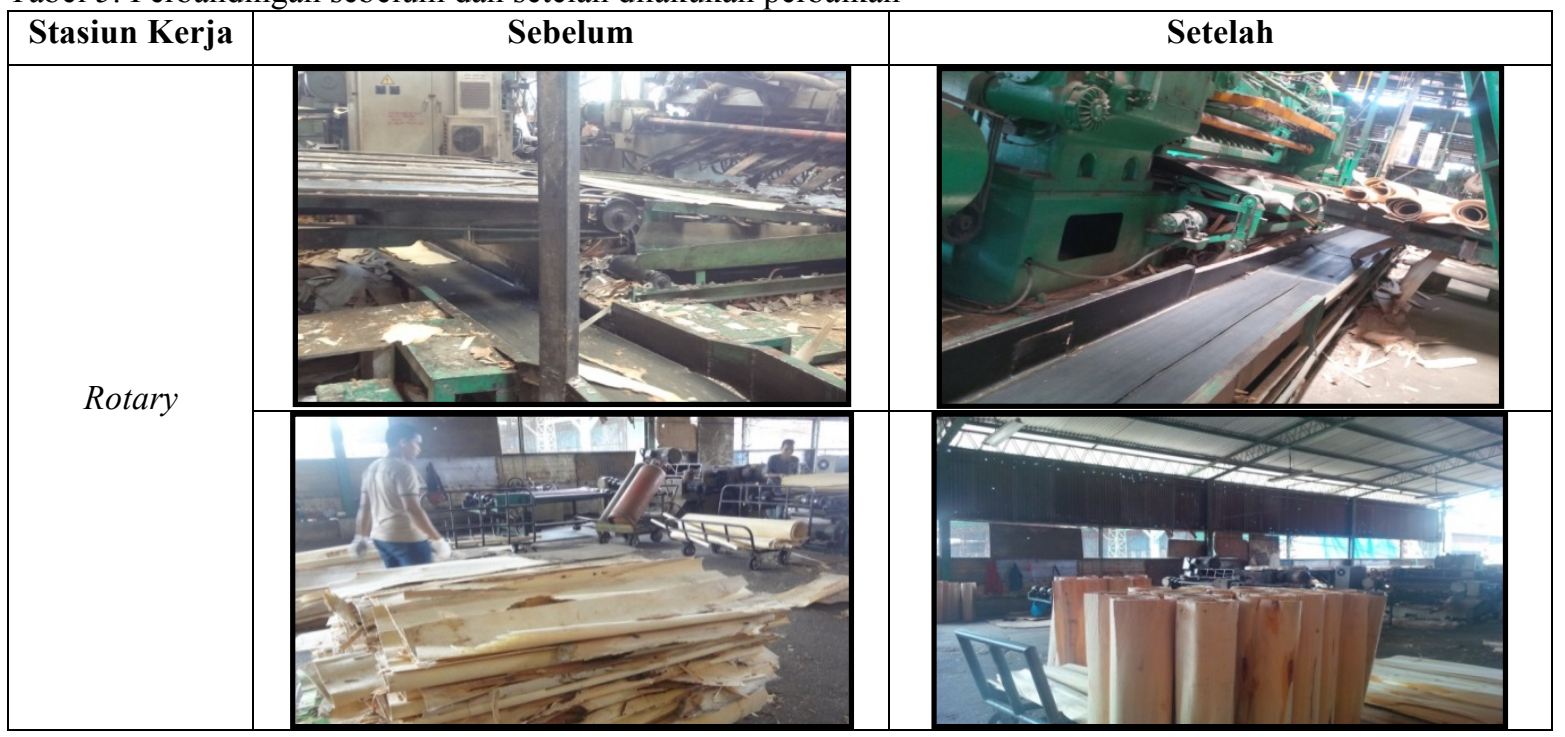




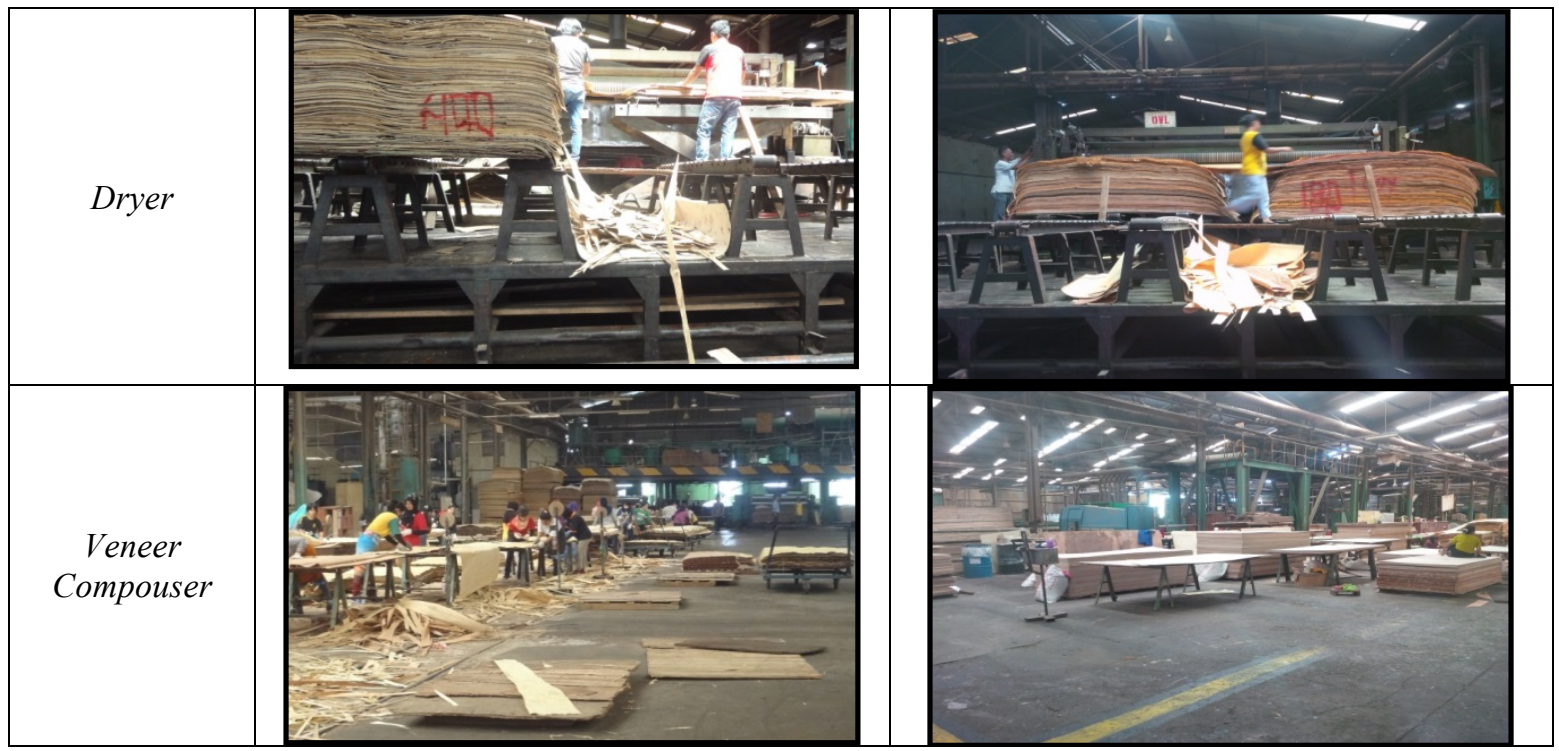

\section{Analisis Keselamatan dan Kesehatan Kerja}

Metode yang digunakan untuk menganalisis mengenai K3 pada PT. Asia Forestama Raya adalah metode HIRARC yang terdiri dari hazard identification, risk assessment, dan risk control.

\section{Hazard Identification (Identifikasi Bahaya)}

Identifikasi bahaya yaitu mengidentifikasi kegiatan yang berbahaya dengan menjabarkan resiko dari setiap kegiatan-kegiatan yang sudah diidentifikasi.

Tabel 6. Identifikasi bahaya

\begin{tabular}{|c|c|}
\hline Faktor bahaya & Sumber Bahaya \\
\hline Kebiasaan & $\begin{array}{c}\text { Pekerja tidak mengecek } \\
\text { mesin atau alat sebelum } \\
\text { dipergunakan }\end{array}$ \\
\hline
\end{tabular}

\begin{tabular}{|c|c|}
\hline Mekanik & $\begin{array}{c}\text { Mesin atau alat yang } \\
\text { digunakan menimbulkan } \\
\text { suara bising }\end{array}$ \\
\hline Fisik & $\begin{array}{c}\text { Pekerja tidak menggunakan } \\
\text { alat pelindung diri }\end{array}$ \\
\hline Elektrik & $\begin{array}{c}\text { Pekerja tidak mengecek } \\
\text { aliran listrik yang mungkin } \\
\text { terhubung }\end{array}$ \\
\hline Ergonomi & $\begin{array}{c}\text { Kondisi dalam bekerja tidak } \\
\text { memenuhi standard ENASE }\end{array}$ \\
\hline Lingkungan & $\begin{array}{c}\text { Lingungan yang penuh } \\
\text { dengan scrap atau sampah } \\
\text { kayu yang tidak dapat } \\
\text { dipergunakan lagi }\end{array}$ \\
\hline Psikologi & $\begin{array}{c}\text { Adanya tekanan yang besar } \\
\text { dari atasan mengenai } \\
\text { pekerjaan }\end{array}$ \\
\hline
\end{tabular}

Setelah dilakukan indentifikasi bahaya selanjutnya adalah melakukan penilaian terhadap risiko-risiko yang terjadi dengan menggunakan skala likelihood dan severity.

Tabel 7. Penilaian risiko

\begin{tabular}{|c|c|c|c|c|c|c|}
\hline Sumber Bahaya & Potensi Bahaya & Potensi Risiko & $\mathrm{L}$ & $\mathrm{S}$ & $\begin{array}{c}\text { Risk } \\
\text { Rating }\end{array}$ & Risiko \\
\hline $\begin{array}{l}\text { Pekerja tidak } \\
\text { mengecek mesin } \\
\text { atau alat } \\
\text { sebelum } \\
\text { dipergunakan }\end{array}$ & $\begin{array}{lr}\text { Pekerja } & \text { bekerja } \\
\text { dalam keadaan } & \text { kondisi } \\
\text { mesin atau } \\
\text { alat yang tidak pasti }\end{array}$ & $\begin{array}{l}\text { 1. Terluka pada bagian tubuh } \\
\text { atau lengan } \\
\text { 2. Pekerja dan proses produksi } \\
\text { menjadi terganggu akibat } \\
\text { kemacetan yang dialami } \\
\text { mesin }\end{array}$ & 4 & 3 & Ekstrim & 12 \\
\hline $\begin{array}{l}\text { Mesin atau alat } \\
\text { yang digunakan } \\
\text { menimbulkan } \\
\text { suara bising }\end{array}$ & $\begin{array}{lr}\text { Pekerja } & \text { bekerja } \\
\text { dalam } & \text { keadan } \\
\text { bising } & \text { yang } \\
\text { ditumbulkan mesin }\end{array}$ & $\begin{array}{l}\text { 1. Mengalami gangguan pada } \\
\text { indra pendengaran } \\
\text { 2. Pekerja mengalami tuli } \\
\text { sebelum waktunya }\end{array}$ & 2 & 3 & Medium & 6 \\
\hline Pekerja tidak & Pekerja bekerja & Kesehatan fisik pekerja menjadi & 4 & 3 & Ekstrim & 12 \\
\hline
\end{tabular}




\begin{tabular}{|c|c|c|c|c|c|c|}
\hline $\begin{array}{l}\text { menggunakan } \\
\text { alat pelindung } \\
\text { diri }\end{array}$ & $\begin{array}{l}\text { dalam kondisi yang } \\
\text { tidak aman }\end{array}$ & terganggu & & & & \\
\hline $\begin{array}{l}\text { Pekerja tidak } \\
\text { mengecek aliran } \\
\text { listrik yang } \\
\text { terhubung }\end{array}$ & $\begin{array}{l}\text { Pekerja bekerja } \\
\text { dalam kondisi yang } \\
\text { belum diketahui } \\
\text { pasti }\end{array}$ & $\begin{array}{l}\text { Terkena sengatan listrik yang } \\
\text { tidak diperhatikan dari awal }\end{array}$ & 1 & 4 & High & 4 \\
\hline $\begin{array}{l}\text { Kondisi dalam } \\
\text { bekerja tidak } \\
\text { memenuhi } \\
\text { standard } \\
\text { ENASE }\end{array}$ & $\begin{array}{l}\text { Pekerja bekerja } \\
\text { dalam kondisi yang } \\
\text { tidak efektif, } \\
\text { nyaman, aman, } \\
\text { sehat dan efisien }\end{array}$ & $\begin{array}{l}\text { 1. Menimbulkan resiko cidera } \\
\text { pada tubuh pekerja dalam } \\
\text { jangka panjang } \\
\text { 2. Kesehatan dan kenyamanan } \\
\text { pekerja terganggu }\end{array}$ & 4 & 2 & High & 8 \\
\hline $\begin{array}{l}\text { Lingungan yang } \\
\text { penuh dengan } \\
\text { scrap atau } \\
\text { sampah kayu } \\
\text { yang tidak dapat } \\
\text { dipergunakan } \\
\text { lagi }\end{array}$ & $\begin{array}{l}\text { Pekerja bekerja } \\
\text { dalam lingkungan } \\
\text { yang kotor dan } \\
\text { penuh dengan debu } \\
\text { scrap kayu }\end{array}$ & 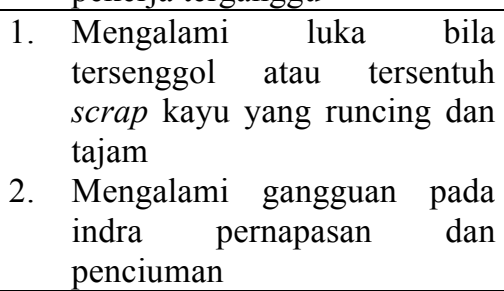 & 4 & 2 & High & 8 \\
\hline $\begin{array}{l}\text { Adanya tekanan } \\
\text { yang besar dari } \\
\text { atasan mengenai } \\
\text { pekerjaan }\end{array}$ & $\begin{array}{lr}\text { Pekerja } & \text { bekerja } \\
\text { dalam } & \text { tekanan } \\
\text { stress } & \text { akibat } \\
\text { kondisi } & \text { lingkungan } \\
\text { kerja } & \\
\end{array}$ & $\begin{array}{l}\text { 1. Kehilangan semangat dan } \\
\text { motivasi kerja } \\
\text { 2. } \begin{array}{l}\text { Menimbulkan stress pada } \\
\text { pekerja }\end{array}\end{array}$ & 2 & 1 & Low & 2 \\
\hline
\end{tabular}

Jika skala likelihood menunjukkan tingkat 1 berarti kegiatan yang terjadi sama atau lebih dari 1 kejadian setiap tahunnya, jika tingkatannya menunjukkan angka 2 berati kejadian tersebut terjadi sama atau lebih dari 1 kejadian setiap bulannya dan jika tingkatannya menunjukkan angka 4 berarti kejadian tersebut terjadi sama atau lebih dari 1 kejadian setiap harinya. Berdasarkan kejadian-kejadian tersebutlah diperoleh tingkatan dalam skala likelihood, pada tabel skala severity jika kejadian yang terjadi berakibat cidera berat maka diberi tingkatan 4, jika cidera yang diperoleh sedang maka diberi tingkatan 3, jika cidera yang terjadi ringan maka pada skala severity diberi tingkatan 2 dan jika tidak terjadi cidera akibat kejadian tersebut maka diberi angka atau tingkatan 1. Dari keterangan-keterangan tersebutlah diperoleh tingkatan-tingkatan beserta deskripnya.

Nilai dari kolom risiko diperoleh dari perkalian antara kolom skala likelihood dan kolom skala severity.

Tabel 8. Rekapitulasi penilaian risiko

\begin{tabular}{|l|c|c|}
\hline \multicolumn{1}{|c|}{ Risk Rating } & Nilai Risiko & Persentase \\
\hline Ekstrim & 24 & 46,15 \\
\hline High & 20 & 38,46 \\
\hline Medium & 6 & 11,54 \\
\hline
\end{tabular}

\begin{tabular}{|l|c|c|}
\hline Low & 2 & 3,85 \\
\hline TOTAL & $\mathbf{5 2}$ & $\mathbf{1 0 0}$ \\
\hline
\end{tabular}

\section{Persentase Penilaian Risiko}

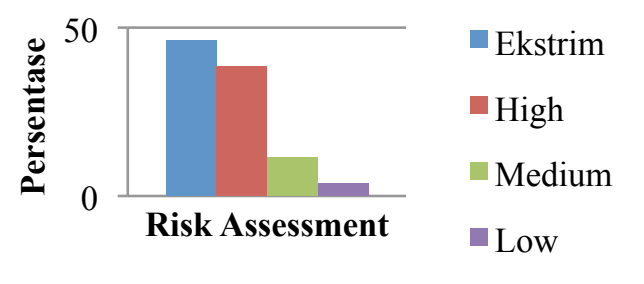

Gambar 2. Grafik Penilaian Risiko

Berdasarkan dari grafik diatas dapat diketahui bahwa penilaian risiko dari kegiatan yang berbahaya pada PT. Asia Forestama Raya yakni $46,15 \%$ pada risiko ekstrim, 38,46\% pada risiko high (tinggi), 11,54\% pada risiko medium (sedang) dan 3,85\% pada risiko low (rendah).

\section{Risk Control (Pengendalian Risiko)}

Risk control bertujuan untuk meminimalkan tingkat risiko dari potensi bahaya yang ada. Pengendalian risiko ini berupa kegiatan yang dilakukan agar bahaya-bahaya yang terjadi tidak akan terjadi lagi untuk masa yang akan datang. 
Tabel 9. Pengendalian risiko

\begin{tabular}{|c|c|c|}
\hline Sumber Bahaya & $\begin{array}{c}\text { Risk } \\
\text { Rating }\end{array}$ & Risk Control \\
\hline $\begin{array}{l}\text { Pekerja tidak } \\
\text { mengecek mesin atau } \\
\text { alat sebelum } \\
\text { dipergunakan }\end{array}$ & Ekstrim & $\begin{array}{l}\text { 1. Membuat SOP dalam menggunakan mesin pada setiap stasiun kerja } \\
\text { 2. Mengadakan seminar mengenai } \mathrm{K} 3 \text { dan peraturan dalam bekerja }\end{array}$ \\
\hline $\begin{array}{l}\text { Mesin atau alat yang } \\
\text { digunakan } \\
\text { menimbulkan suara } \\
\text { bising }\end{array}$ & Medium & $\begin{array}{l}\text { 1. Mewajibkan pekerja menggunakan alat pelindung telinga dari suara } \\
\text { bising } \\
\text { 2. Memberi sanksi dan teguran tegas kepada karyawan yang tidak } \\
\text { menggunakan alat pelindung diri } \\
\text { 3. Mengadakan seminar mengenai K3 dan peraturan dalam bekerja }\end{array}$ \\
\hline $\begin{array}{lr}\text { Pekerja } & \text { tidak } \\
\text { menggunakan } & \text { alat } \\
\text { pelindung diri } & \end{array}$ & Ekstrim & $\begin{array}{l}\text { 1. Mewajibkan pekerja menggunakan alat pelindung diri } \\
\text { 2. Memberi sanksi dan teguran tegas kepada karyawan yang tidak } \\
\text { menggunakan alat pelindung diri } \\
\text { 3. Mengadakan seminar mengenai K3 dan peraturan dalam bekerja }\end{array}$ \\
\hline $\begin{array}{l}\text { Pekerja } \\
\text { mengecek } \\
\text { listrik } \\
\text { terhubung }\end{array}$ & High & $\begin{array}{l}\text { 1. Membuat SOP penggunaan mesin pada setiap stasiun kerja } \\
\text { 2. Mewajibkan pekerja menggunakan alat pelindung diri } \\
\text { 3. Memberi sanksi dan teguran tegas kepada karyawan yang tidak } \\
\text { menggunakan alat pelindung diri } \\
\text { 4. Mengadakan seminar mengenai K3 dan peraturan dalam bekerja }\end{array}$ \\
\hline $\begin{array}{l}\text { Kondisi dalam } \\
\text { bekerja tidak } \\
\text { memenuhi standard } \\
\text { ENASE }\end{array}$ & High & $\begin{array}{l}\text { 1. Menyesuaikan jarak pekerja dengan mesin yang lebih ergonomi } \\
\text { 2. Mengadakan seminar mengenai K3 dan peraturan dalam bekerja }\end{array}$ \\
\hline $\begin{array}{l}\text { Lingungan yang } \\
\text { penuh dengan scrap } \\
\text { atau sampah kayu } \\
\text { yang tidak dapat } \\
\text { dipergunakan lagi }\end{array}$ & High & $\begin{array}{l}\text { 1. Membuat jadwal piket pembersihan stasiun kerja } \\
\text { 2. Mewajibkan pekerja menggunakan alat pelindung diri } \\
\text { 3. Memberi sanksi dan teguran tegas kepada karyawan yang tidak } \\
\text { menggunakan alat pelindung diri } \\
\text { 4. Mengadakan seminar mengenai K3 dan peraturan dalam bekerja }\end{array}$ \\
\hline $\begin{array}{l}\text { Adanya tekanan yang } \\
\text { besar dari atasan } \\
\text { mengenai pekerjaan }\end{array}$ & Low & $\begin{array}{l}\text { 1. Mengurangi tekanan pada diri pekerja } \\
\text { 2. Meningkatkan kembali motivasi pekerja dengan mengadakan } \\
\text { seminar dan menghadirkan motivator handal } \\
\text { 3. Mengadakan seminar mengenai K3 dan peraturan dalam bekerja }\end{array}$ \\
\hline
\end{tabular}

Risk rating diperoleh berdasarkan skala risk rating yaitu persilangan antara frekuensi risiko yaitu dengan menggunakan skala likelihood dan dampak dari risiko dengan skala severity. Jika pada skala likelihood menunjukkan angka 4 dan skala severity menunjukkan angka 3 itu berarti kejadian tersebut adalah kejadian yang ekstrim, jika skala likelihood menunjukkan angka 2 dan skala severity menunjukkan angka 3 berarti kejadian tersebut adalah kejadian yang medium, jika skala likelihood menunjukkan angka 1 dan skala severity menunjukkan angka 4 berarti kejadian tersebut adalah kejadian yang high atau tinggi, jika skala likelihood menunjukkan angka 4 dan skala severity menunjukkan angka 2 berarti kejadian tersebut adalah kejadian yang high atau tinggi, dan jika skala likelihood menunjukkan angka 2 dan skala severity menunjukkan angka 1 berarti kejadian tersebut adalah kejadian yang bersifat low atau rendah.

\section{Kesimpulan}

Melalui penerapan metode $5 \mathrm{~S}$ pada perusahaan kondisi lingkungan kerja menjadi lebih rapi, lebih tertata dan lebih bersih dari sbelumnya, maka hal tersebut dapat menimbulkan kenyamanan terhadap pekerja dalam bekerja.Mengenai keselamatan dan kesehatan kerja, hasil identifikasi bahaya yang diperoleh dilihat berdasarkan faktor atau kategori bahaya yaitu berdasarkan bahaya kebiasaan, bahaya mekanik, bahaya fisik, bahaya elektrik, bahaya ergonomi, bahaya lingkungan dan bahaya psikologi. Dari hasil risk assessment yang dilakukan diperoleh 46,15 \% kegiatan yang memiliki potensi bahaya ekstrim, 38,46 \% kegiatan yang memiliki potensi bahaya high (tinggi), 11,54\% kegiatan yang memiliki potensi bahaya medium (sedang) dan 3,85\% kegiatan yang memiliki potensi bahaya low (rendah). Pengendalian risiko yang diusulkan antara lain membuat SOP penggunaan mesin, melakukan 
seminar mengenai pentingnya K3, mewajibkan penggunaan alat pelindung diri serta pemberian sanksi terhadap pelanggaran peraturan perusahaan, dan membuat jadwal piket terhadap penjagaan kebersihan.

\section{Daftar Pustaka}

[1] Ariani, F. Analisis Postur Kerja dalam Sistem Manusia Mesin untuk Mengurangi Fatigue Akibat Kerja pada Bagian Air Traffic Control (ACT) di PT. Angkasa Pura II Polonia Medan. Jurnal Dinamis Vol. II, No, 6, Januari 2010. Medan: Universitas Sumatera Utara, 2010.

[2] Gunawan, Bendatu. Perbaikan Keselamatan dan Kesehatan Kerja Dengan Metode HIRARC di PT. Sumber Rubberindo Jaya. Jurnal Tirta Volume 3 Nomor 2 Juni 2015 pp 421-426, 2015.

[3] Hudori, Rambe. Analisis Faktor Penyebab Kecelakaan Kerja Dan Kerugian Yang Timbul Akibat Jam Kerja Yang Hilang. Jurnal Sistem Teknik Industri Volume 4 Nomor 7 Januari 2003. Medan: Universitas Sumatera Utara, 2013.

[4] Nurmianto, Eko. Ergonomi Konsep Dasar dan Aplikasinya. Jakarta: Penerbit Guna Widya, 2008.

[5] Rahman, R, S. Perancangan 5S (Seiri, Seiton, Seiso, Seiketsu, Shitsuke) Pada Industri Roti (Studi Kasus Home Industri Muri Naga), Pekanbaru: Universitas Islam Negeri Sultan Syarif Kasim Riau. Tugas Akhir, 2013.

[6] Ramli, Soehatman. Pedoman Praktis Manajemen Resiko dalam Perspektif K3 OHS Risk Management. Jakarta: PT. Dian Rakyat. 2010.

[7] Rimawan, Sutowo. 2015. Analisa Penerapan 5 s+Safety Pada Areawarehouse di PT. Multifilling Mitra Indonesia. Jurnal Ilmiah PASTI Volume VI Edisi 1- ISSN 2085-5869. Jakarta: Teknik Industri Universitas Mercubuana.

[8] Risma, Hemita. Usulan Perbaikan Metode Kerja Berdasarkan Micromotion Study dan Penerapan Metode 5S untuk Meningkatkan Produktifitas. Yogyakarta: Institut Sains dan Teknologi AKPRIND. Jurnal Teknologi Volume 1 Nomor 2,Desember 2008 191-203, 2009.

[9] Siska, Henriadi. Perancangan Fasilitas Pabrik Tahu untuk Meminimalisasi Material Handling.Jurnal Teknik Industri, Vol. 13, No.2, Agustus 2012: 133-141. Pekanbaru: Teknik Industri Fakultas Sains dan
Teknologi UIN Sultan Syarif Kasim Riau, 2012.

[10] Suwondo, Chandra. Penerapan Budaya Kerja 5S (Seiri, Seiton, Seiso, Seiketsu, Shitsuke) di Indonesia. Jurnal Magister Manajemen Volume 1 Nomor 1 April 2012 29-48. Jakarta: Universitas Borobudur, 2012.

[11] Wijaya, Togar, Herry. Evaluasi Kesehatan dan Keselamatan Kerja dengan Metode HIRARC pada PT. Charoen Pokphand Indonesia. Jurnal Tirta Volume 3 Nomor 1 Januari 2015 pp 29-34, 2015.

[12] Wignjosoebroto, Sritomo. Ergonomi Studi Gerak dan Waktu. Surabaya: Guna Widya, 2008.

[13] Wiranata, Edi. Redesain Kursi Kuliah Ergonomis denganb Pendekatan Anthropometri. Tugas Akhir. Surakarta: Universitas Sebelas Maret, 2011.

[14] Wiratmani, Elfitria. Analisis Implementasi Metode 5s Untuk Pemeliharaan Stasiun Kerja Proses Silk Printing Di Pt. Mandom Indonesia Tbk. ISSN: 1979-276X. Jakarta: Universitas Indraprasta PGRI, 2013. 